\title{
Relationships between GAT1 and PTSD, Depression, and Substance Use Disorder
}

\author{
Kaitlin E. Bountress ${ }^{1}$, Wei Wei ${ }^{2}$, Christina Sheerin ${ }^{3}$, Dongjun Chung ${ }^{2}$, Ananda B. Amstadter ${ }^{3}$, \\ Howard Mandel ${ }^{4}$ and Zhewu Wang ${ }^{1,4, *}$ \\ 1 Department of Psychiatry, Medical University of South Carolina, Charleston, SC 29425, USA; \\ bountres@musc.edu \\ 2 Department of Public Health Sciences, Medical University of South Carolina, \\ Charleston, SC 29425-8350, USA; weiwe@musc.edu (W.W.); chungd@musc.edu (D.C.) \\ 3 Virginia Institute for Psychiatry and Behavioral Genetics, Virginia Commonwealth University, \\ Richmond, VA 23219-1534, USA; Christina.sheerin@gmail.com (C.S.); \\ Ananda.Amstadter@vcuhealth.org (A.B.A.) \\ 4 Ralph H. Johnson VA Medical Center, Charleston, SC 29401, USA; mandel@musc.edu \\ * Correspondence: wanzh@musc.edu; Tel.: +1-843-792-7135 \\ Academic Editor: Bruno Aouizerate \\ Received: 19 August 2016; Accepted: 20 December 2016; Published: 5 January 2017
}

\begin{abstract}
Post-traumatic stress disorder (PTSD), Major Depressive Disorder (MDD), and Substance Use Disorder (SUD) have large public health impacts. Therefore, researchers have attempted to identify those at greatest risk for these phenotypes. PTSD, MDD, and SUD are in part genetically influenced. Additionally, genes in the glutamate and gamma-aminobutyric acid (GABA) system are implicated in the encoding of emotional and fear memories, and thus may impact these phenotypes. The current study examined the associations of single nucleotide polymorphisms in GAT1 individually, and at the gene level, using a principal components (PC) approach, with PTSD, PTSD comorbid with MDD, and PTSD comorbid with SUD in 486 combat-exposed veterans. Findings indicate that several GAT1 SNPs, as well as one of the GAT1 PCs, was associated with PTSD, with and without MDD and SUD comorbidity. The present study findings provide initial insights into one pathway by which shared genetic risk influences PTSD-MDD and PTSD-SUD comorbidities, and thus identify a high-risk group (based on genotype) on whom prevention and intervention efforts should be focused.
\end{abstract}

Keywords: GAT1; post-traumatic stress disorder; major depressive disorder; substance use disorder; veterans

\section{Introduction}

There exists a notable, and important, disconnect between rates of traumatic event exposure and development of negative outcomes such as post-traumatic stress disorder (PTSD). Given the fact that only a subset of individuals go on to develop the intense and prolonged stress response characterized by PTSD, great interest exists in identifying individual differences that confer this risk. Among those risk factors of interest, individual genetic differences represent an important etiologic source of variability in risk, supported by extant lines of evidence from family, twin, and molecular genetic studies [1].

The molecular genetics literature on PTSD, which seeks to identify specific genetic variation that may account for increased risk for the phenotype given trauma exposure, has grown substantially over the last two decades, with over 120 molecular genetic associations published to date (see [2,3] for reviews). Although genome-wide association studies that agnostically examine polymorphisms across the entire genome are increasing in frequency, the vast majority of extant molecular genetic 
studies have utilized a candidate gene design. In this design, selection of the gene(s) is informed by existing biological evidence, targeting polymorphisms (i.e., genetic variation) within and around the gene region of interest. Genes examined from biological candidate systems in relation to PTSD have included polymorphisms of genes from the dopaminergic system (e.g., DAT1, DRD2 [4]), the promoter region of the serotonin transporter system (5-HTTLPR [5]), and the hypothalamic pituitary adrenal axis (i.e., stress-response) system (e.g., glucocorticoid receptor [6]), among others. These studies have met with varying success and there is much still unknown about the molecular genetic architecture of PTSD.

\subsection{Glutamate/GABA Systems and Risk for PTSD}

More recently, there has been increased interest in examining genes related to the glutamate and $\gamma$-aminobutyric acid (GABA) systems in informing our understanding of the genetic underpinnings of PTSD [7]. Existing preclinical animal studies support the notion that the GABAergic system regulates the intensity and duration of the stress response and plays a role in controlling the epigenetic and gene transcriptional responses to psychological stress (see [8]) as well as being involved in the encoding of emotional and fear memories $[9,10]$.

Under the assumption that GABA levels in the brain are genetically predetermined, findings of differential GABA levels in individuals with PTSD suggest that this may represent preexisting vulnerability to stress-related disorders such as PTSD [11]. Thus, examination of genetic variation within this gene and its association with PTSD would further our understanding of the GABAergic system in relation to PTSD as well as our understanding of genetic risk of this system as a vulnerability marker for PTSD. Within the GABAergic system, the GABA transporters (GATs) are key molecules in GABAergic transmission. GATs control the duration and intensity of GABAergic activity at the synapse, through reuptake of released GABA [12]. There are four GABA transporter subtypes, GAT1, GAT2, GAT3, and GAT4, with GAT1 coding for GAT1, which is considered the major subtype and presents both at synaptic and extrasynaptic sites in the brain $[13,14]$. Variation in the GAT1 gene may play a part in impacting predisposition to negative outcomes following trauma, which has been supported in animal models of anxiety [12] and learning/memory (e.g., [15]). This work is clearly still in its infancy, as a review of the literature suggests that, to date, there have been no clinical investigations of the association between GAT1 and PTSD.

\subsection{The GABA System and Other Psychiatric Comorbidities}

The extant literature suggests that much of the demonstrated genetic influences on PTSD overlap with those of other conditions, particularly depression [16]. These shared genetic influences may underlie the frequent comorbid presentation of these disorders. Given the role of the GABA system in the brain and in response to stressors, as well as associations of GABA activity in a range of emotional and cognitive factors, it is unsurprising that variation in this system has been suggested as a potential marker that may cut across clinical diagnostic categories [15]. In particular, GABA abnormalities have been associated with Major Depressive Disorder (MDD; e.g., [17-19]). If the GABA system is involved in the encoding of emotional and fear memories $[9,10]$, individuals at greater genetic risk on GAT1 may show increased propensity for comorbid PTSD-MDD, rather than just PTSD alone.

In addition to the high degree of comorbidity between PTSD and MDD, PTSD and substance use disorders (SUDs) also frequently co-occur [20-22]. The extant literature suggests that many of the demonstrated genetic influences on PTSD overlap with those of alcohol $[23,24]$ and drug use disorders [25]. Additionally, many individuals with PTSD use alcohol and drugs in order to avoid aversive emotional symptoms (i.e., "self-medication" [26]). Given GABA's role in regulating stress response [8] and encoding emotional and fear memories [9,10], it may be that variation in GAT1 represents a potential shared genetic risk for both greater trauma-related anxiety (i.e., greater severity of PTSD symptoms) and use/misuse of substances following trauma exposure. Because of the paucity 
of work on GABA system genes and SUD, we will examine GAT1's impact on PTSD-SUD comorbidity in an exploratory manner.

\subsection{Current Study}

The first aim of the present investigation was to examine the association between GAT1 with PTSD in a trauma-exposed sample. Specifically, the current study tests the hypothesis that GAT1 variation, utilizing both single nucleotide polymorphisms (SNPs) and principle components comprised of these polymorphisms, will significantly predict PTSD diagnosis. The second aim of this study is to examine whether GAT1 variation underlies risk for comorbid PTSD and MDD. It is hypothesized that GAT1 will be significantly associated with comorbid PTSD-MDD diagnosis, such that those at higher genetic risk will be more likely to meet criteria for both PTSD and MDD, rather than just PTSD alone. The final (and exploratory) aim of this study is to examine whether SNPs within the GAT1 gene underlie increased risk for comorbid PTSD and SUDs, over and above the risk for PTSD alone. Specifically, the current study tests whether individuals at higher genetic risk on GAT1 are more likely to meet criteria for PTSD and SUD, compared to PTSD alone. This project aims to expand upon existing work through the use of multiple SNPs and principle components as measures of genetic risk. It also examines whether these genetic effects influence PTSD, PTSD and MDD, or PTSD and SUD, over and above the covariates with established impact on outcomes including age, sex, race, and combat exposure severity.

\section{Materials and Methods}

\subsection{Participants}

A total of 519 combat veterans, recruited through the Cincinnati Veterans Affairs Medical Center (VAMC) and Charleston VAMC, were enrolled in the study. Participants were eligible for inclusion if they had a history of combat exposure, and if they did not meet criteria for lifetime DSM-IV schizophrenia, bipolar disorder, or active substance abuse or dependence in the past six months. Of the 519 enrolled, genotype data were missing for 33 individuals, who were thus excluded. The 486 remaining participants were included in study analyses. Of these $486,82 \%$ were male, $69 \%$ were Caucasian, and all were between the ages of 21-80. All 486 were in the control or PTSD group, all of whom experienced combat exposure. Attempts were made to match the trauma-exposure severity between these two groups. Specifically, all control participants from the Charleston VAMC and a majority of control participants from the Cincinnati VA were required to have Combat Exposure Scale (CES) scores of 10 or more. All control subjects were also selected to be free of Axis I disorders. Additional information about control and PTSD study participants has been previously reported [27].

\subsection{Procedure}

All subjects gave their informed consent for inclusion before they participated in the study. The study was conducted in accordance with the Declaration of Helsinki, and the research protocol was approved by the Institutional Review Boards (IRB) of both the University of Cincinnati and Medical University of South Carolina. Demographic and deployment information was collected after participants provided consent. PTSD symptoms, as well as other major psychiatric disorders, were assessed by a board-certified psychiatrist. Additional interview and self-report measures were implemented to capture additional information (e.g., combat exposure information).

\subsection{Measures}

See Table 1 for descriptive information on study constructs. 
Table 1. Demographic and clinical characteristics of sample.

\begin{tabular}{cccc}
\hline Variable & Control $(\boldsymbol{n = 1 7 2 )}$ & PTSD $(\boldsymbol{n = 3 1 4})$ & $\boldsymbol{p}$ \\
\hline Age & $43.2 \pm 14.7$ & $43.5 \pm 14.4$ & 0.820 \\
CES & $19.5 \pm 8.7$ & $21.7 \pm 10.5$ & 0.020 \\
\hline Race & & & 0.001 \\
CA & $127(26.1 \%)$ & $207(42.6 \%)$ & \\
AA & $27(5.6 \%)$ & $91(18.7 \%)$ & \\
Other & $18(3.7 \%)$ & $16(3.3 \%)$ & \\
Sex & & & 0.056 \\
Male & $133(27.4 \%)$ & $266(54.7 \%)$ & \\
Female & $39(8.0 \%)$ & $48(9.9 \%)$ & $<0.001$ \\
Depression & $166(34.2 \%)$ & $111(22.8 \%)$ & \\
No depression & $6(1.2 \%)$ & $203(41.8 \%)$ & \\
Depression & $166(34.2 \%)$ & $215(44.2 \%)$ & \\
\hline Substance Use Disorder & $6(1.2 \%)$ & $99(20.4 \%)$ & \\
No abuse & & & \\
Abuse & & & \\
\hline
\end{tabular}

Notes: For continuous variables, mean $\pm \mathrm{SD}$ are shown. For categorical variables, $n(\%)$ are shown. Statistically significant associations $(p<0.05)$ are marked in red. PTSD = those with Posttraumatic Stress Disorder. CES = Combat Exposure Scale, $\mathrm{CA}=$ Caucasians, $\mathrm{AA}=$ African-Americans .

\subsubsection{Age, Sex, and Race}

Because the relationships among study variables tend to vary across age, sex, and race [28-30], these constructs were used as covariates in study models. Specifically, individuals self-reported on age in years, sex, and race. In order to examine the effects of race on study outcomes, two dummy-coded variables were created. The first compared Caucasians to African-Americans, and the second compared Caucasians to those who self-identified as a race other than Caucasian or African-American.

\subsubsection{Combat Exposure Scale}

The Combat Exposure Scale (CES; [31]) is a seven-item self-report measure used to obtain information regarding exposure to wartime stressful events. The measure has total scores ranging from 1 to 41 , with a higher number reflecting higher severity of combat exposure.

\subsubsection{Post-Traumatic Stress Disorder}

Participants were interviewed using the clinician administered PTSD Scale (CAPS [32]), a structured diagnostic interview for current and lifetime PTSD that assesses all 17 symptoms of PTSD for frequency and intensity. Those who endorsed at least one re-experiencing symptom, three or more avoidance symptoms, and two or more hyperarousal symptoms met the criteria for DSM-IV PTSD.

\subsubsection{Depression}

Participants were interviewed using the Hamilton Rating Scale for Depression (Ham-D [33]), a 17-item semi-structured interview for current Depression. Individuals who received scores of 20 or higher met criteria were considered to meet criteria for depression.

\subsubsection{Substance Use Disorder}

Participants were interviewed about their lifetime substance use using by a board-certified psychiatrist with either the Structured Clinical Interview for DSM-IV (SCID [34]) or the Mini-International Neuropsychiatric Interview (MINI [35]). 


\subsubsection{SNP Selection and Genotyping}

Genomic DNA was extracted from blood samples using a Wizard Genomic DNA purification kit (Promega, Madison, WI, USA) using the manufacturer's protocol. Sixteen SNPs thought to be representative in terms of coverage of the entire GAT1 gene, as well as those that were not in complete linkage disequilibrium with others within the gene, were included. Additionally, variants with minor allele frequencies greater than or equal to $10 \%$, and covering a region of $50 \mathrm{~kb}$ in the NET gene were included (upstream promoter region of NET gene and spanning $46 \mathrm{kB}$ toward the $3^{\prime}$ end of the SLC1A1 gene using a software tool (SNPbrowser version 4.0; Applied Biosystems, Foster City, CA, USA). Additional information on genotyping can be found in author et al. [27]. Table 2 provides a summary of the 16 SNPs examined in this study including their genotype frequencies and $p$-values for testing Hardy-Weinberg Equilibrium (HWE) by race. No violation of HWE assumptions were detected after the Bonferroni correction. Table 2 also lists the $p$-values for comparing the genotype frequencies between African-Americans and Caucasians.

Table 2. List of SNPs with their genotype frequency, and $p$-values of testing for Hardy-Weinberg equilibrium by race.

\begin{tabular}{|c|c|c|c|c|c|c|c|}
\hline \multirow{2}{*}{ SNP } & \multirow{2}{*}{$\begin{array}{c}\text { Rare } \\
\begin{array}{c}\text { Homozygotes } \\
(\%)\end{array} \\
\end{array}$} & \multirow{2}{*}{ Heterozygotes (\%) } & \multirow{2}{*}{$\begin{array}{c}\text { Common } \\
\text { Homozygotes } \\
(\%)\end{array}$} & \multicolumn{3}{|c|}{ Hardy-Weinberg $p$-Value } & \multirow{2}{*}{$\begin{array}{c}\text { Genotype } \\
\text { Frequency by } \\
\text { Race } p \text {-Value }\end{array}$} \\
\hline & & & & CA & AA & Others & \\
\hline rs2928078 & 33.7 & 50.0 & 16.3 & 0.377 & 0.289 & 0.504 & 0.002 \\
\hline rs2933308 & 44.2 & 42.4 & 13.4 & 0.559 & 1.000 & 0.478 & 0.008 \\
\hline rs720352 & 29.7 & 50.2 & 20.1 & 0.322 & 1.000 & 0.741 & 0.726 \\
\hline rs1919075 & 58.3 & 34.7 & 7.0 & 1.000 & 0.005 & 0.167 & $<0.001$ \\
\hline rs 2697150 & 58.0 & 35.2 & 6.8 & 0.753 & 0.188 & 1.000 & 0.086 \\
\hline rs2697134 & 74.2 & 24.4 & 1.4 & 0.006 & 0.203 & 0.042 & 0.014 \\
\hline rs11707097 & 73.0 & 23.9 & 3.2 & 0.821 & 0.340 & 0.113 & 0.343 \\
\hline rs2675163 & 62.2 & 33.8 & 4.0 & 0.766 & 0.690 & 1.000 & 0.001 \\
\hline rs2697149 & 57.6 & 35.5 & 6.9 & 0.643 & 0.261 & 1.000 & 0.183 \\
\hline rs1728816 & 41.3 & 43.8 & 14.9 & 0.243 & 1.000 & 0.722 & 0.699 \\
\hline rs2697153 & 51.6 & 38.0 & 10.4 & 0.481 & 0.143 & 0.298 & $<0.001$ \\
\hline rs2944367 & 59.6 & 32.0 & 8.4 & 0.024 & 0.013 & 0.690 & 0.051 \\
\hline rs9876005 & 83.5 & 12.6 & 3.9 & 0.001 & 0.300 & 0.146 & $<0.001$ \\
\hline rs9879137 & 78.0 & 18.1 & 3.9 & 0.103 & 0.406 & 0.371 & $<0.001$ \\
\hline rs 2272403 & 64.7 & 26.1 & 9.2 & 0.161 & 0.001 & 1.000 & $<0.001$ \\
\hline rs11925331 & 78.0 & 18.5 & 3.5 & 0.059 & 0.270 & 0.371 & $<0.001$ \\
\hline
\end{tabular}

\subsection{Data Analytic Plan}

A preliminary analysis was conducted to examine the differences between the control group and PTSD cases in terms of demographic information (age, sex, and race), as well as the association with MDD, SUD, and amount of combat exposure (via the CES). T-tests and chi-square tests were used for preliminary analysis. The primary analysis assessed the risk of three different outcomes: the presence of PTSD (i.e., including all of PTSD without MDD/SUD, PTSD with MDD, and PTSD with SUD), the comorbidity of PTSD and MDD, and the comorbidity of PTSD and SUD. The association between each SNP and PTSD was analyzed using logistic regression after adjusting for the effects of age, sex, race, and CES. Proportional odds models were used to study the association between each SNP and each of the comorbidities after adjusting for demographic variables and CES. The key assumption of the proportional odds model is that the coefficients that describe the relation between the categories lower than or equivalent to a certain category versus the categories higher than this category in the response variable are the same for all categories in the response variable [36]. Our proportional odds models predict membership in the ordered categories: no PTSD, PTSD without comorbidities, and PTSD with comorbidities.

After we fitted the model for each of 16 SNPs, a Bonferroni correction was employed to adjust their PTSD association $p$-values for multiple testing. To control for familywise type I error rate, we adjusted $p$ values using the Bonferroni approach for the 16 SNPs but not for the three outcomes, because the Bonferroni adjustment is known to be somewhat conservative, especially when the tests 
are correlated [37]. Based on this procedure, and given the significance level of $\alpha=0.05$ for each SNP, we determined a SNP to be associated with each outcome if $p<0.003$.

Given the limited sample size in our study, it was possible that we were under powered to reach significance. To address this issue, we also considered a gene-based association analysis that improves statistical power by sharing information across multiple SNPs. For this gene-based analysis, we employed a principal component (PC) approach that has been shown to be superior than the haplotype based approaches in terms of having better power to identify gene-disease association and producing less biased estimates [38]. For this approach, we constructed PCs using the allele counts of all 16 SNPs after standardizing allele counts of each SNP, and included the first several PCs with the largest variances in the model to represent the gene.

For these analyses, we included only Caucasian participants. This decision was made because the genotype frequencies were significantly different between African-Americans and Caucasians as shown in Table 2. Additionally, because African-Americans only made up $24.3 \%$ of the study cohort, the analyses on this small group of participants may have been underpowered and/or the estimates may not be stable or representative of the larger group of African-Americans.

Within these analyses on Caucasians, we considered the first four principal components (PC1, PC2, PC3, and PC4) in our analysis because they explained $57 \%$ of genotype variance (i.e., $19 \%, 15 \%$, $13 \%$, and $10 \%$, respectively). (The fifth and sixth components explained $8 \%$ and $6 \%$ of the variance, respectively. We chose the number of components by plotting the percent variance associated with each PC). The PC approach is not only known to effectively capture the LD information within a gene, but it is also easy to implement, and is reported to be more powerful than other genotype- or haplotype-based approaches such as the ranked sum score approach [36,37]. The association between the first four principal components and each of the three outcomes was assessed using logistic regression or proportional odds logistic regression, similar to those described above.

\section{Results}

In terms of demographic and clinical descriptive comparisons, there were no statistically significant differences between PTSD cases and controls with regard to age $(p=0.820)$. However, CES $(p=0.020)$ and race $(p=0.001)$ were found to be predictors of PTSD status, with sex being a marginally significant predictor $(p=0.056)$. Specifically, subjects with higher CES, African-Americans, and males were at higher risk for PTSD. MDD $(p<0.001)$ and SUD $(p<0.001)$ were predictive of PTSD. Out of the 314 PTSD cases, 203 (64.6\%) cases were also diagnosed with MDD, 99 (31.5\%) cases had a history of SUD, and $78(24.8 \%)$ cases had PTSD without MDD or SUD, whereas only six out of the 172 controls $(3.5 \%)$ had MDD or SUD.

\subsection{SNP Level Association}

Table 3 summarizes the effect of each SNP on risk for PTSD, the comorbidity of PTSD and MDD, and the comorbidity of PTSD and SUD, respectively. Although the analyses presented in Table 3 pertain to the whole sample, results of Caucasian-specific and African-American-specific analyses can be viewed in Appendix Tables A1 and A2, respectively. The PTSD analysis results based on logistic regression analysis indicate that the minor allele of rs720352 (OR $=1.35,95 \% \mathrm{CI}: 1.01-1.81, p=0.045$ ) and $\mathrm{rs} 2272403(\mathrm{OR}=1.45,95 \% \mathrm{CI}: 1.01-2.10, p=0.046)$ increased the risk of PTSD, whereas the minor allele of rs1919075 (OR $=0.65,95 \%$ CI: 0.47-0.89, $p=0.008$ ) reduced the risk of PTSD, after adjusting for age, race, sex, and CES, although these results did not remain significant after the Bonferroni correction for multiple testing. In the comorbidity analysis for PTSD and MDD based on the proportional odds model, the minor allele of rs1919075 also reduced the odds of having PTSD or PTSD-MDD (OR $=0.71$, 95\% CI: 0.53-0.94, $p=0.018$ ), adjusting for age, race, sex and CES. Specifically, for patients with the minor allele of rs1919075, their odds of having PTSD-MDD versus having PTSD alone or no PTSD are $29 \%$ lower compared to patients without this minor allele given age, race, sex and CES are held 
constant. Likewise, their odds of having PTSD or PTSD-MDD versus no PTSD is 29\% lower compared to patients without this minor allele, given other variables in the model are held constant.

Table 3. The effect of each SNP on the risk of PTSD (i.e., individuals with only Posttraumatic Stress Disorder), PTSD-MDD (i.e., comorbid Posttraumatic Stress Disorder and Major Depressive Disorder), and PTSD-SUD (i.e., comorbid Posttraumatic Stress Disorder and Substance Use Disorder), adjusting for age, race, sex and CES.

\begin{tabular}{|c|c|c|c|c|c|c|c|c|c|c|c|c|}
\hline \multirow[b]{2}{*}{ SNP } & \multicolumn{4}{|c|}{ PTSD } & \multicolumn{4}{|c|}{ PTSD-MDD } & \multicolumn{4}{|c|}{ PTSD-SUD } \\
\hline & OR & $\begin{array}{l}95 \% \\
\text { Lower } \\
\text { CI }\end{array}$ & $\begin{array}{l}95 \% \\
\text { Upper } \\
\text { CI }\end{array}$ & $p$ & OR & $\begin{array}{l}95 \% \\
\text { Lower } \\
\text { CI }\end{array}$ & $\begin{array}{l}95 \% \\
\text { Upper } \\
\text { CI }\end{array}$ & $p$ & OR & $\begin{array}{l}95 \% \\
\text { Lower } \\
\text { CI }\end{array}$ & $\begin{array}{l}95 \% \\
\text { Upper } \\
\text { CI }\end{array}$ & $p$ \\
\hline rs2928078 & 1.28 & $0.96-$ & 1.73 & 0.097 & 1.24 & 0.96 & 1.61 & 0.097 & 1.32 & 1.02 & 1.71 & 0.033 \\
\hline rs2933308 & 1.26 & 0.94 & 1.70 & 0.120 & 1.19 & 0.92 & 1.54 & 0.184 & 1.33 & 1.03 & 1.73 & 0.028 \\
\hline rs720352 & 1.35 & 1.01 & 1.81 & 0.045 & 1.17 & 0.91 & 1.51 & 0.211 & 1.27 & 0.99 & 1.63 & 0.064 \\
\hline rs1919075 & 0.65 & 0.47 & 0.89 & 0.008 & 0.71 & 0.53 & 0.94 & 0.018 & 0.66 & 0.49 & 0.89 & 0.006 \\
\hline rs2697150 & 0.92 & 0.67 & 1.28 & 0.625 & 0.92 & 0.70 & 1.22 & 0.570 & 0.88 & 0.66 & 1.16 & 0.347 \\
\hline rs2697134 & 0.80 & 0.53 & 1.23 & 0.306 & 0.73 & 0.50 & 1.06 & 0.096 & 0.76 & 0.52 & 1.11 & 0.158 \\
\hline rs11707097 & 1.08 & 0.74 & 1.61 & 0.692 & 1.05 & 0.75 & 1.46 & 0.797 & 1.00 & 0.72 & 1.40 & 0.993 \\
\hline rs2675163 & 1.22 & 0.86 & 1.75 & 0.268 & 1.28 & 0.93 & 1.75 & 0.127 & 1.10 & 0.81 & 1.51 & 0.540 \\
\hline rs2697149 & 1.02 & 0.74 & 1.43 & 0.895 & 1.01 & 0.76 & 1.34 & 0.960 & 0.97 & 0.73 & 1.28 & 0.824 \\
\hline rs1728816 & 0.95 & 0.71 & 1.26 & 0.717 & 0.95 & 0.74 & 1.22 & 0.708 & 0.94 & 0.73 & 1.21 & 0.651 \\
\hline rs2697153 & 1.08 & 0.79 & 1.47 & 0.637 & 1.02 & 0.78 & 1.33 & 0.904 & 1.10 & 0.84 & 1.44 & 0.503 \\
\hline rs2944367 & 0.89 & 0.65 & 1.20 & 0.433 & 0.91 & 0.70 & 1.19 & 0.485 & 0.90 & 0.68 & 1.18 & 0.427 \\
\hline rs9876005 & 1.27 & 0.76 & 2.20 & 0.369 & 1.22 & 0.81 & 1.85 & 0.348 & 1.07 & 0.72 & 1.59 & 0.729 \\
\hline rs9879137 & 1.01 & 0.64 & 1.59 & 0.982 & 1.11 & 0.76 & 1.62 & 0.587 & 0.93 & 0.65 & 1.33 & 0.682 \\
\hline rs2272403 & 1.45 & 1.01 & 2.10 & 0.046 & 1.44 & 1.07 & 1.95 & 0.018 & 1.16 & 0.87 & 1.55 & 0.304 \\
\hline rs11925331 & 1.37 & 0.87 & 2.22 & 0.183 & 1.31 & 0.90 & 1.91 & 0.156 & 1.05 & 0.73 & 1.50 & 0.803 \\
\hline
\end{tabular}

Notes: The association between individual SNP and PTSD is based on logistic regression analysis. The association between individual SNP and PTSD-MDD or PTSD-SUD is based on proportional odds model. Statistically significant associations $(p<0.05)$ are marked in red.

The minor allele of rs2272403 (OR $=1.44,95 \%$ CI: 1.07-1.95, $p=0.018$ ) significantly increased the odds of having PTSD or PTSD-MDD, with all the other variables in the model held constant. In contrast, the minor allele of $\mathrm{rs} 2928078(\mathrm{OR}=1.32,95 \% \mathrm{CI}: 1.02-1.71, p=0.033)$ and rs2933308 $(\mathrm{OR}=1.33,95 \% \mathrm{CI}: 1.03-1.73, p=0.028)$ significantly increased the odds of having PTSD or PTSD-SUD, adjusting for age, race, sex, and CES, whereas the minor allele of rs1919075 reduced the odds of having PTSD or PTSD-SUD (OR = 0.66, 95\% CI: 0.49-0.89, $p=0.006)$. These findings were also not significant after Bonferroni correction $(p<0.003)$.

The association between each of the 16 SNPs and the three outcomes (PTSD, PTSD-MDD, and PTSD-SUD) were also examined by race. Similar findings were obtained for Caucasians, whereas a smaller number of SNPs significantly predicted these outcomes among African-Americans.

\subsection{Gene Level Association}

Interrogation of the loading matrix (Table 4) indicated that PC1 is mostly associated with rs2928078, rs2933308, rs720352, and rs1919075, which is consistent with LD structure among Caucasians. These SNPs are predictive of PTSD, PTSD-MDD, or PTSD-SUD. Specifically, PC1 was inversely associated with rs2928078 $(\varrho=-0.51)$, rs2933308 $(\varrho=-0.46)$, rs720352 $(\varrho=-0.46)$, and positively associated with rs1919075 $(\varrho=0.39)$. Hence, the association between PC1 and outcomes of interest found in Caucasians represents the overall effect of SNPs located at GAT1 gene on PTSD, PTSD-MDD, and PTSD-SUD, respectively.

Table 5 shows the gene-level analysis results based on the PC approach. Among the four principal components we considered, PC1 was significantly associated with PTSD (OR = 0.84, 95\% CI: 0.73-0.96, $p=0.012$ ) among Caucasians, after adjusting for age, sex, and CES. Based on the proportional odds model, PC1 was also significantly associated with risk of PTSD or PTSD-MDD (OR $=0.88$, 95\% CI: 0.78-0.99, $p=0.033$ ) after adjusting for age, sex and CES. Similarly, PC1 was significantly associated with the risk of PTSD or PTSD-SUD (OR = 0.86, 95\% CI: 0.76-0.97, $p=0.015)$ after adjusting for age, sex, and CES. Age, sex, and CES were not significantly associated with any of the three outcomes. (To verify the validity of our PCA approach, we additionally considered the genetic 
risk sum score (GRSS) [39] to examine the gene level association with phenotypes. Specifically, GRSS is calculated by the summation of the number of risk alleles across SNPs divided by the number of SNPs in the score, where risk alleles are determined based on $p$-values after filtering out highly correlated SNPs. We calculated GRSS based on a $p$-value cutoff point of 0.05 , and included the GRSS as a predictor in our multivariate logistic and proportional odds models. We found that a higher number of risk alleles is associated with increased risk of PTSD, PTSD-MDD, and PTSD-SUD (see Appendix Table A3).) As with the previous analyses initially found to be significant $(p<0.05)$, these results were not significant after Bonferroni correction $(p<0.003)$.

Table 4. Loading of each SNP on the first four principal components used in the gene-level analysis.

\begin{tabular}{ccccc}
\hline & PC1 & PC2 & PC3 & PC4 \\
\hline rs2928078 & -0.511 & 0.052 & 0.100 & 0.133 \\
rs2933308 & -0.459 & 0.153 & 0.123 & 0.144 \\
rs720352 & -0.460 & 0.102 & -0.019 & 0.086 \\
rs1919075 & 0.393 & 0.124 & -0.082 & 0.088 \\
rs2697150 & -0.051 & 0.347 & -0.517 & 0.030 \\
rs2697134 & -0.086 & -0.102 & -0.017 & -0.189 \\
rs11707097 & -0.285 & -0.085 & -0.027 & -0.098 \\
rs2675163 & -0.003 & -0.035 & 0.053 & 0.288 \\
rs2697149 & -0.042 & 0.349 & -0.540 & 0.012 \\
rs1728816 & 0.082 & -0.300 & 0.147 & 0.576 \\
rs2697153 & -0.041 & 0.100 & 0.385 & -0.560 \\
rs2944367 & -0.038 & 0.042 & 0.079 & 0.367 \\
rs9876005 & 0.009 & -0.413 & -0.269 & -0.069 \\
rs9879137 & -0.054 & -0.474 & -0.246 & -0.074 \\
rs2272403 & -0.187 & -0.332 & -0.161 & -0.143 \\
rs11925331 & -0.145 & -0.281 & -0.267 & -0.077 \\
\hline
\end{tabular}

Notes: Loadings of absolute values larger than 0.35 are marked in red.

Table 5. Gene-level association with PTSD (i.e., individuals with only Posttraumatic Stress Disorder), PTSD-MDD (i.e., comorbid Posttraumatic Stress Disorder and Major Depressive Disorder), and PTSD-SUD (i.e., comorbid Posttraumatic Stress Disorder and Substance Use Disorder), adjusting for age, sex, and CES in Caucasians.

\begin{tabular}{|c|c|c|c|c|c|c|c|c|c|c|c|c|}
\hline & \multicolumn{4}{|c|}{ PTSD } & \multicolumn{4}{|c|}{ PTSD-MDD } & \multicolumn{4}{|c|}{ PTSD-SUD } \\
\hline & OR & $\begin{array}{l}95 \% \\
\text { Lower } \\
\text { CI }\end{array}$ & $\begin{array}{l}95 \% \\
\text { Upper } \\
\text { CI }\end{array}$ & $p$-Value & OR & $\begin{array}{l}95 \% \\
\text { Lower } \\
\text { CI }\end{array}$ & $\begin{array}{l}95 \% \\
\text { Upper } \\
\text { CI }\end{array}$ & $p$-Value & OR & $\begin{array}{l}95 \% \\
\text { Lower } \\
\text { CI }\end{array}$ & $\begin{array}{l}95 \% \\
\text { Upper } \\
\text { CI }\end{array}$ & $p$-Value \\
\hline Age & 1.00 & 0.98 & 1.02 & 0.951 & 1.00 & 0.98 & 1.01 & 0.715 & 1.01 & 0.99 & 1.02 & 0.477 \\
\hline Female & 0.79 & 0.43 & 1.44 & 0.429 & 0.81 & 0.47 & 1.39 & 0.440 & 0.64 & 0.37 & 1.09 & 0.101 \\
\hline CES & 1.01 & 0.98 & 1.03 & 0.534 & 1.01 & 0.99 & 1.03 & 0.249 & 1.01 & 0.99 & 1.03 & 0.481 \\
\hline PC1 & 0.84 & 0.73 & 0.96 & 0.012 & 0.88 & 0.78 & 0.99 & 0.033 & 0.86 & 0.76 & 0.97 & 0.015 \\
\hline
\end{tabular}

\section{Discussion}

The current study had three aims. First, we examined whether GAT1 variation significantly predicted PTSD diagnosis. Second, we tested the hypothesis that GAT1 would be significantly associated with comorbid PTSD-MDD diagnoses. Finally, we investigated whether individuals at higher genetic risk on GAT1 would be more likely to meet the criteria for PTSD and SUD. Each of these aims will be discussed in turn.

In examining the relationships between single SNPs and each of the PCs and PTSD, we found preliminary evidence that PC1 was significantly associated with PTSD diagnosis. These findings are consistent with research suggesting that GAT1 may impact anxious behaviors $[12,13]$ and fear extinction [9] in rats. The findings also add to the limited work examining the impact of transporters 
in the GABA and glutamate systems on PTSD diagnosis in veterans (i.e., the SNP rs10739062 predicted PTSD diagnosis; [27]). Thus, the current study findings provide preliminary support for the impact of GAT1 on emotion/fear-based memories in veterans.

In testing the second study hypothesis, PC1 was associated with increased risk for comorbid PTSD and MDD diagnoses, over PTSD without MDD. This finding is consistent with prior animal work suggesting that GAT1 may impact both anxiety and depression-like behaviors [12,19]. However, this study is the first to find that these SNPs in particular may impact PTSD-MDD comorbidity. We also add to the literature by suggesting that GAT1 underlies some shared generalized risk (e.g., altered mood/fear-based behavior post-trauma) that is associated with risk for both PTSD and MDD. Future work should seek to identify specifics of this shared risk and endophenotypes, with the aim of pinpointing one target for interventions to prevent both PTSD and MDD post-trauma.

In terms of the final and exploratory aim, PC1 predicted increased propensity for comorbid PTSD and SUD diagnoses, over PTSD without SUD, over and above study covariates including severity of trauma exposure. This finding is consistent with the larger literature implicating shared genetic risk in propensity for this PTSD-SUD comorbidity [24]. However, these findings are the first to find that some of these GAT1 SNPs impact PTSD-SUD comorbidity. They also add to this work by identifying GAT1 as one mechanism by which risk for both PTSD and SUD is conferred.

We also examined the relationship between 16 SNPs and our three outcomes (PTSD, PTSD-MDD, and PTSD-SUD). None of these associations reached our a priori significance threshold.

\section{Strengths and Limitations}

Despite the current study's strengths, including the use of a powerful PC approach to capturing genetic risk, it is important to acknowledge its limitations. First, our data are cross-sectional. Therefore, the temporal associations among these phenotypes are unclear. Specifically, individuals at higher risk on GAT1 may have been more likely to experience PTSD post-trauma, and then subsequently develop MDD and/or SUD. Moreover, SUD was, by study design, only lifetime and not current. Alternatively, individuals at higher risk on GAT1 may have been more likely to meet the criteria for MDD or SUD, in turn increasing their vulnerability to PTSD post-trauma. More research is needed to test more specifically how GAT1 might influence these comorbidities. Additionally, the current study findings cannot rule out the possibility that some unmeasured confounder (e.g., potentially another gene that is associated with GAT1) explains the risk for PTSD-MDD or PTSD-SUD. The findings also cannot rule out the possibility that the effect of PC1 is being driven by a single SNP. Finally, without including ancestry informative markers, population stratification may have occurred. However, this explanation is rendered less likely by our inclusion of race as a covariate in the SNP-based analyses and the gene level analyses being limited to Caucasians.

\section{Conclusions}

Despite these limitations, the current study extends the previous research in a few ways. First, these findings provide initial suggestive evidence that those at greater genetic risk on GAT1 are at increased risk for PTSD and MDD as well as PTSD and SUD, compared to just risk for PTSD alone. Therefore, those with a greater number of risk alleles on GAT1 comprise a particularly risky group, on whom prevention and intervention efforts should be focused. Given the paucity of work examining the link between GAT1 SNPs and these phenotypes, this work is incredibly important, as it provides initial insight into SNPs that may account for the shared genetic overlap in PTSD, MDD, and SUD.

Acknowledgments: This work was supported by Ralph H. Johnson VA Medical Center and the Clinical Sciences Program of the Department of Veterans Affairs Merit Review Grant (No. 1I01CX000487-01A1). Dongjun Chung is supported by the National Institute of General Medical Sciences R01 grant GM122078 and the National Cancer Institute R21 grant CA209848. Kaitlin E. Bountress and Christina Sheerin are supported by National Institute of Mental Health T32 grants MH18869 (KB) and MH020030 (CS). Ananda B. Amstadter is supported by grants R01AA020179, K02 AA023239, BBRF 20066, R21 MH103686, R01MH101518, and P60MD002256. 
Author Contributions: K.E.B. wrote the method and discussion; W.W. performed the data analysis, and wrote the data analytic plan and results; C.S. wrote the introduction; D.C., A.B.A., and Z.W. provided critical revisions; Z.W. additionally developed the study concept and performed the data collection. All authors read and approved the final version of the paper for submission.

Conflicts of Interest: The authors declare no conflict of interest.

\section{Appendix}

Table A1. The effect of each SNP on the risk of PTSD (i.e., individuals with only Posttraumatic Stress Disorder), PTSD-MDD (i.e., comorbid Posttraumatic Stress Disorder and Major Depressive Disorder), and PTSD-SUD (i.e., comorbid Posttraumatic Stress Disorder and Substance Use Disorder) in Caucasians, adjusting for age, sex and CES.

\begin{tabular}{|c|c|c|c|c|c|c|c|c|c|c|c|c|}
\hline \multirow[b]{2}{*}{ SNP } & \multicolumn{4}{|c|}{ PTSD } & \multicolumn{4}{|c|}{ PTSD-MDD } & \multicolumn{4}{|c|}{ PTSD-SUD } \\
\hline & OR & $\begin{array}{l}95 \% \\
\text { Lower } \\
\text { CI }\end{array}$ & $\begin{array}{c}95 \% \\
\text { Upper } \\
\text { CI }\end{array}$ & $p$ & OR & $\begin{array}{l}95 \% \\
\text { Lower } \\
\text { CI }\end{array}$ & $\begin{array}{c}95 \% \\
\text { Upper } \\
\text { CI }\end{array}$ & $p$ & OR & $\begin{array}{l}95 \% \\
\text { Lower } \\
\text { CI }\end{array}$ & $\begin{array}{c}95 \% \\
\text { Upper } \\
\text { CI }\end{array}$ & $p$ \\
\hline rs2928078 & 1.31 & 0.94 & 1.84 & 0.12 & 1.20 & 0.89 & 1.62 & 0.23 & 1.35 & 1.00 & 1.83 & 0.05 \\
\hline rs2933308 & 1.16 & 0.84 & 1.63 & 0.38 & 1.12 & 0.83 & 1.51 & 0.47 & 1.32 & 0.98 & 1.78 & 0.07 \\
\hline rs720352 & 1.36 & 0.97 & 1.92 & 0.08 & 1.34 & 0.99 & 1.83 & 0.06 & 1.30 & 0.96 & 1.76 & 0.09 \\
\hline rs1919075 & 0.57 & 0.39 & 0.82 & 0.00 & 0.67 & 0.48 & 0.93 & 0.02 & 0.63 & 0.45 & 0.88 & 0.01 \\
\hline rs2697150 & 0.97 & 0.66 & 1.43 & 0.88 & 0.93 & 0.65 & 1.32 & 0.67 & 0.99 & 0.70 & 1.40 & 0.94 \\
\hline rs2697134 & 1.05 & 0.64 & 1.75 & 0.86 & 0.88 & 0.57 & 1.38 & 0.59 & 0.94 & 0.60 & 1.47 & 0.78 \\
\hline rs11707097 & 1.17 & 0.74 & 1.89 & 0.51 & 1.04 & 0.69 & 1.55 & 0.86 & 1.02 & 0.68 & 1.53 & 0.92 \\
\hline rs2675163 & 1.19 & 0.81 & 1.76 & 0.38 & 1.45 & 1.01 & 2.07 & 0.04 & 1.08 & 0.76 & 1.53 & 0.68 \\
\hline rs2697149 & 1.13 & 0.77 & 1.67 & 0.55 & 1.08 & 0.76 & 1.52 & 0.68 & 1.03 & 0.73 & 1.46 & 0.86 \\
\hline rs1728816 & 0.75 & 0.54 & 1.04 & 0.09 & 0.87 & 0.65 & 1.17 & 0.36 & 0.79 & 0.59 & 1.07 & 0.13 \\
\hline rs2697153 & 1.19 & 0.85 & 1.67 & 0.31 & 1.08 & 0.80 & 1.45 & 0.61 & 1.21 & 0.90 & 1.62 & 0.22 \\
\hline rs2944367 & 0.92 & 0.65 & 1.30 & 0.63 & 0.97 & 0.71 & 1.32 & 0.84 & 0.88 & 0.64 & 1.20 & 0.42 \\
\hline rs9876005 & 1.05 & 0.45 & 2.75 & 0.92 & 1.29 & 0.56 & 2.98 & 0.55 & 0.75 & 0.36 & 1.58 & 0.45 \\
\hline rs9879137 & 0.98 & 0.52 & 1.94 & 0.96 & 1.14 & 0.62 & 2.10 & 0.67 & 0.79 & 0.45 & 1.39 & 0.41 \\
\hline rs2272403 & 1.89 & 1.14 & 3.25 & 0.02 & 1.87 & 1.20 & 2.90 & 0.01 & 1.35 & 0.90 & 2.03 & 0.15 \\
\hline rs11925331 & 2.42 & 1.17 & 5.70 & 0.03 & 1.99 & 1.10 & 3.61 & 0.02 & 1.28 & 0.75 & 2.18 & 0.37 \\
\hline
\end{tabular}

Table A2. The effect of each SNP on the risk of PTSD (i.e., individuals with only Posttraumatic Stress Disorder), PTSD-MDD (i.e., comorbid Posttraumatic Stress Disorder and Major Depressive Disorder), and PTSD-SUD (i.e., comorbid Posttraumatic Stress Disorder and Substance Use Disorder) in African-Americans, adjusting for age, sex and CES.

\begin{tabular}{|c|c|c|c|c|c|c|c|c|c|c|c|c|}
\hline \multirow[b]{2}{*}{ SNP } & \multicolumn{4}{|c|}{ PTSD } & \multicolumn{4}{|c|}{ PTSD-MDD } & \multicolumn{4}{|c|}{ PTSD-SUD } \\
\hline & OR & $\begin{array}{l}95 \% \\
\text { Lower } \\
\text { CI } \\
\end{array}$ & $\begin{array}{c}95 \% \\
\text { Upper } \\
\text { CI } \\
\end{array}$ & $p$ & OR & $\begin{array}{l}95 \% \\
\text { Lower } \\
\text { CI }\end{array}$ & $\begin{array}{c}95 \% \\
\text { Upper } \\
\text { CI } \\
\end{array}$ & $p$ & OR & $\begin{array}{l}95 \% \\
\text { Lower } \\
\text { CI }\end{array}$ & $\begin{array}{c}95 \% \\
\text { Upper } \\
\text { CI } \\
\end{array}$ & $p$ \\
\hline rs2928078 & 1.85 & 0.81 & 4.56 & 0.16 & 1.87 & 0.98 & 3.55 & 0.06 & 1.59 & 0.86 & 2.96 & 0.14 \\
\hline rs2933308 & 2.00 & 0.87 & 5.10 & 0.12 & 1.39 & 0.76 & 2.54 & 0.29 & 1.43 & 0.79 & 2.60 & 0.24 \\
\hline rs720352 & 1.06 & 0.51 & 2.24 & 0.87 & 0.63 & 0.37 & 1.08 & 0.10 & 1.05 & 0.62 & 1.77 & 0.85 \\
\hline rs1919075 & 1.99 & 0.61 & 11.89 & 0.33 & 1.12 & 0.53 & 2.40 & 0.76 & 1.00 & 0.48 & 2.07 & 1.00 \\
\hline rs2697150 & 1.15 & 0.54 & 2.60 & 0.73 & 1.26 & 0.72 & 2.19 & 0.42 & 0.76 & 0.45 & 1.28 & 0.30 \\
\hline rs2697134 & 0.39 & 0.12 & 1.18 & 0.10 & 0.40 & 0.16 & 1.00 & 0.05 & 0.39 & 0.15 & 1.01 & 0.05 \\
\hline rs11707097 & 0.95 & 0.39 & 2.33 & 0.90 & 1.09 & 0.54 & 2.20 & 0.81 & 0.95 & 0.48 & 1.87 & 0.88 \\
\hline rs2675163 & 0.71 & 0.23 & 2.36 & 0.55 & 0.51 & 0.23 & 1.17 & 0.11 & 0.63 & 0.27 & 1.47 & 0.28 \\
\hline rs2697149 & 1.07 & 0.48 & 2.60 & 0.87 & 1.16 & 0.64 & 2.10 & 0.63 & 0.94 & 0.54 & 1.66 & 0.84 \\
\hline rs1728816 & 1.61 & 0.76 & 3.66 & 0.23 & 0.87 & 0.51 & 1.47 & 0.60 & 1.35 & 0.77 & 2.34 & 0.29 \\
\hline rs2697153 & 0.71 & 0.26 & 2.13 & 0.51 & 0.86 & 0.39 & 1.92 & 0.71 & 0.81 & 0.37 & 1.76 & 0.59 \\
\hline rs2944367 & 0.47 & 0.21 & 1.06 & 0.07 & 0.56 & 0.30 & 1.05 & 0.07 & 0.61 & 0.32 & 1.16 & 0.13 \\
\hline rs9876005 & 1.18 & 0.57 & 2.56 & 0.66 & 1.02 & 0.60 & 1.72 & 0.95 & 1.22 & 0.73 & 2.06 & 0.45 \\
\hline rs9879137 & 0.82 & 0.39 & 1.74 & 0.60 & 0.95 & 0.56 & 1.61 & 0.84 & 1.01 & 0.59 & 1.70 & 0.99 \\
\hline rs2272403 & 0.82 & 0.43 & 1.53 & 0.53 & 0.94 & 0.59 & 1.51 & 0.81 & 0.82 & 0.52 & 1.30 & 0.40 \\
\hline rs11925331 & 0.84 & 0.40 & 1.80 & 0.65 & 0.98 & 0.56 & 1.72 & 0.96 & 0.81 & 0.47 & 1.39 & 0.44 \\
\hline
\end{tabular}

Notes: For African Americans, only one SNP was found to be significant at a significance level of 0.05 . Because African-Americans only made up $24.3 \%$ of the study cohort, the analyses on this small group of participants may have been under-powered and/or the estimates may not be stable or representative of the larger group of African-Americans. Statistically significant association $(p<0.05)$ is marked in red. 
Table A3. Results using Genetic Risk Sum Score (GRSS).

\begin{tabular}{|c|c|c|c|c|c|c|c|c|c|c|c|c|}
\hline & \multicolumn{4}{|c|}{ PTSD } & \multicolumn{4}{|c|}{ PTSD-MDD } & \multicolumn{4}{|c|}{ PTSD-SUD } \\
\hline & OR & $\begin{array}{c}95 \% \\
\text { Lower } \\
\text { CI }\end{array}$ & $\begin{array}{c}95 \% \\
\text { Upper } \\
\text { CI }\end{array}$ & $p$-Value & OR & $\begin{array}{c}95 \% \\
\text { Lower } \\
\text { CI }\end{array}$ & $\begin{array}{c}95 \% \\
\text { Upper } \\
\text { CI }\end{array}$ & $p$-Value & OR & $\begin{array}{c}95 \% \\
\text { Lower } \\
\text { CI }\end{array}$ & $\begin{array}{c}95 \% \\
\text { Upper } \\
\text { CI }\end{array}$ & $p$-Value \\
\hline Age & 1.00 & 0.98 & 1.02 & 0.943 & 1.00 & 0.98 & 1.01 & 0.760 & 1.01 & 0.99 & 1.02 & 0.465 \\
\hline Female & 0.78 & 0.43 & 1.44 & 0.426 & 0.79 & 0.46 & 1.36 & 0.393 & 0.63 & 0.37 & 1.08 & 0.097 \\
\hline CES & 1.01 & 0.98 & 1.03 & 0.576 & 1.01 & 0.99 & 1.03 & 0.319 & 1.01 & 0.99 & 1.03 & 0.493 \\
\hline GRSS & 2.50 & 1.46 & 4.39 & 0.001 & 2.19 & 1.36 & 3.55 & 0.001 & 1.65 & 1.13 & 2.42 & 0.009 \\
\hline
\end{tabular}

Notes: The gene-level association with PTSD (i.e., those with only Posttraumatic Stress Disorder) is based on logistic regression analysis. The gene-level association with PTSD-MDD (i.e., comorbid PTSD-Major Depression) or PTSD-SUD (i.e., comorbid PTSD-Substance Use Disorder) is based on proportional odds model. $\mathrm{CES}=$ Combat Exposure Scale. Statistically significant association $(p<0.05)$ is marked in red.

\section{References}

1. Smoller, J.W. The Genetics of Stress-Related Disorders: PTSD, Depression, and Anxiety Disorders. Neuropsychopharmacology 2015, 41, 297-319. [CrossRef] [PubMed]

2. Almli, L.M.; Fani, N.; Smith, A.K.; Ressler, K.J. Genetic approaches to understanding post-traumatic stress disorder. Int. J. Neuropsychopharmacol. 2013, 17, 355-370. [CrossRef] [PubMed]

3. Voisey, J.; Young, R.M.; Lawford, B.R.; Morris, C.P. Progress towards understanding the genetics of posttraumatic stress disorder. J. Anxiety Disord. 2014, 28, 873-883. [CrossRef] [PubMed]

4. Li, L.; Bao, Y.; He, S.; Wang, G.; Guan, Y.; Ma, D.; Wang, P.; Huang, X.; Tao, S.; Zhang, D.; et al. The association between genetic variants in the dopaminergic system and posttraumatic stress disorder: A meta-analysis. Medicine 2016, 95, e3074. [CrossRef] [PubMed]

5. Navarro-Mateu, F.; Escámez, T.; Koenen, K.C.; Alonso, J.; Sánchez-Meca, J. Meta-analyses of the 5-HTTLPR polymorphisms and post-traumatic stress disorder. PLoS ONE 2013, 8, e66227. [CrossRef] [PubMed]

6. Castro-Vale, I.; van Rossum, E.F.C.; Machado, J.C.; Mota-Cardoso, R.; Carvalho, D. Genetics of glucocorticoid regulation and posttraumatic stress disorder-What do we know? Neurosci. Biobehav. Rev. 2016, 63, 143-157. [CrossRef] [PubMed]

7. Sanacora, G.; Treccani, G.; Popoli, M. Towards a glutamate hypothesis of depression: An emerging frontier of neuropsychopharmacology for mood disorders. Neuropharmacology 2012, 62, 63-77. [CrossRef] [PubMed]

8. Reul, J. Making memories of stressful events: A journal along epigenetic, gene transcriptions, and signaling pathways. Front. Psychiatry 2014, 5. [CrossRef] [PubMed]

9. Corcoran, K.; Maren, S. Hippocampal inactivation disrupts contextual retrieval of fear memory after extinction. J. Neurosci. 2001, 21, 1720-1726.

10. DeLorey, T.M.; Lin, R.C.; McBrady, B.; He, X.; Cook, J.M.; Lameh, J.; Loew, G.H. Influence of benzodiazepine binding site ligands on fear-conditioned contextual memory. Eur. J. Pharmacol. 2001, 426, 45-54. [CrossRef]

11. Vaiva, G.; Thomas, P.; Ducrocq, F.; Fontaine, M.; Boss, V.; Devos, P.; Rascle, C.; Cottencin, O.; Brunet, A.; Laffargue, P.; et al. Low posttrauma GABA plasma levels as a predictive factor in the development of acute posttraumatic stress disorder. Biol. Psychiatry 2004, 55, 250-254. [CrossRef] [PubMed]

12. Liu, G.X.; Cai, G.Q.; Cai, Y.Q.; Sheng, Z.J.; Jiang, J.; Mei, Z.; Wang, Z.G.; Guo, L.; Fei, J. Reduced Anxiety and Depression-Like Behaviors in Mice Lacking GABA Transporter Subtype 1. Neuropsychopharmacology 2007, 32, 1531-1539. [CrossRef] [PubMed]

13. Shi, J.; Cai, Y.; Guoxiang, L.; Gong, N.; Liu, Z.; Xu, T.; Wang, Z.; Fei, J. Enhanced learning and memory in GAT1 heterozygous mice. Acta Biochim. Biophys. Sin. 2012, 44, 359. [CrossRef] [PubMed]

14. Guastella, J.; Nelson, N.; Nelson, H.; Czyzyk, L.; Keynan, S.; Miedel, M.C.; Davidson, N.; Lester, H.A.; Kanner, B.I. Cloning and expression of a rat brain GABA transporter. Science 1990, 249, 1303-1306. [CrossRef] [PubMed]

15. Rosso, I.M.; Weiner, M.R.; Crowley, D.J.; Silveri, M.M.; Rauch, L.; Jensen, J.E. Insula and anterior cingulate GABA levels in post-traumatic stress disorder: Preliminary findings using magnetic resonance spectroscopy. Depression Anxiety 2014, 31, 115-123. [CrossRef] [PubMed] 
16. Sartor, C.E.; Grant, J.D.; Lynskey, M.T.; McCutcheon, V.V.; Waldron, M.; Statham, D.J.; Bucholz, K.K.; Madden, P.A.; Heath, A.C.; Martin, N.G.; et al. Common heritable contributions to low-risk trauma, high-risk trauma, posttraumatic stress disorder, and major depression. Arch. Gen. Psychiatry 2012, 69, 293-299. [CrossRef] [PubMed]

17. Brambilla, P.; Perez, J.; Barale, F.; Schettini, G.; Soares, J. GABAergic dysfunction in mood disorders. Mol. Psychiatry 2003, 8, 721-737. [CrossRef] [PubMed]

18. Tunnicliff, G.; Malatynska, E. Central GABAergic systems and depressive illness. Neurochem. Res. 2003, 28, 965-976. [CrossRef] [PubMed]

19. Sanacora, G.; Saricicek, A. GABAergic contributions to the pathophysiology of Depression and the mechanism of antidepressant action. CNS Neurolo. Disord. 2007, 6, 127-140. [CrossRef]

20. Head, M.; Goodwin, L.; Debell, F.; Greenberg, N.; Wessely, S.; Fear, N.T. PTSD and alcohol misuse: Comorbidity in UK military personnel. Soc. Psychiatry Psychiatr. Epidemiol. 2016, 51, 1171-1180. [CrossRef] [PubMed]

21. Petrakis, I.L.; Rosenheck, R.; Desai, R. Substance use comorbidity among Veterans with PTSD and other psychiatric illness. Am. J. Addict. 2011, 20, 185-189. [CrossRef] [PubMed]

22. Jacobsen, L.K.; Southwick, S.M.; Kosten, T.R. Substance Use Disorders in Patients with PTSD: A review of the literature. Am. J. Psychiatry 2001, 158, 1184-1190. [CrossRef] [PubMed]

23. McLeod, D.S.; Koenen, K.C.; Meyer, J.M.; Lyons, M.J.; Eisen, S.; True, W.; Goldberg, J. Genetic and environmental influences on the relationship among combat exposure, posttraumatic stress disorder symptoms, and alcohol use. J. Trauma. Stress 2001, 14, 259-275. [CrossRef] [PubMed]

24. Sartor, C.E.; McCutcheon, V.V.; Pommer, N.E.; Nelson, E.C.; Grant, J.D.; Duncan, A.E.; Waldron, M.; Bucholz, K.K.; Madden, P.; Heath, A. Common genetic and environmental contributions to posttraumatic stress disorder and alcohol dependence in young women. Psychol. Med. 2011, 41, 1497-1505. [CrossRef] [PubMed]

25. Xian, H.; Chantarujikapong, S.I.; Scherrer, J.F.; Eisen, S.A.; Lyons, M.J.; Goldberg, J.; Tsuang, M.; True, W.R. Genetic and environmental influences on posttraumatic stress disorder, alcohol and drug dependence in twin pairs. Drug Alcohol Depend. 2000, 61, 95-102. [CrossRef]

26. Simpson, T.L.; Stappenbeck, C.A.; Luterek, J.A.; Lehavot, K.; Kaysen, D.L. Drinking motives moderate daily relationships between PTSD symptoms and alcohol use. J. Abnorm. Psychol. 2014, 123, 237-247. [CrossRef] [PubMed]

27. Zhang, J.; Sheerin, C.; Mandel, H.; Banducci, A.N.; Myrick, H.; Acierno, R.; Amstadter, A.B.; Wang, Z. Variation in SLC1A1 is related to combat-related posttraumatic stress disorder. J. Anxiety Disord. 2014, 28, 902-907. [CrossRef] [PubMed]

28. Ditlevsen, D.N.; Elklit, A. The combined effect of gender and age on PTSD: Do men and women show differences in the lifespan of the disorder. Ann. Gen. Psychiatry 2010, 9, 1-12. [CrossRef] [PubMed]

29. Frueh, B.C.; Brady, K.L.; de Arellano, M.A. Racial differences in combat-related PTSD: Empirical findings and conceptual issues. Clin. Psychol. Rev. 1998, 18, 287-305. [CrossRef]

30. Olff, M.; Langeland, W.; Draijer, N.; Gersons, B.P.R. Gender differences in PTSD. Psychol. Bull. 2007, 133, 183-204. [CrossRef] [PubMed]

31. Keane, T.M.; Fairbank, J.A.; Caddell, J.M.; Zimering, R.T.; Taylor, K.L.; Mora, C.A. Clinical Evaluation of a Measure to Asses Combat Exposure. Psychol. Assess. J. Consult. Clin. Psychol. 1989, 1, 53-55.

32. Blake, D.D.; Weathers, F.W.; Nagy, L.M.; Kaloupek, D.G.; Gusman, F.D.; Charney, D.S.; Keane, T.M. The development of a Clinician-Administered PTSD Scale. J. Trauma. Stress 1995, 8, 75-90. [CrossRef] [PubMed]

33. Hamilton, M. A rating scale for depression. J. Neurol. Neurosurg. Psychiatry 1960, 23, 56-62. [CrossRef] [PubMed]

34. First, M.B.; Gibbon, M.; Spitzer, R.L.; Williams, J.B.W. User's Guide for the Structured Clinical Interview for DSM-IV Axis I Disorders-Research Version; Biometrics Research Department, New York State Psychiatric Institute: New York, NY, USA, 1996.

35. Sheehan, D.V.; Lecrubier, Y.; Sheehan, K.H.; Amorim, P.; Janavs, J.; Weiller, E.; Hergueta, T.; Baker, R.; Dunbar, G.C. The Mini-International Neuropsychiatric Interview (MINI): The development and validation of a structured diagnostic psychiatric interview for DSM-IV and ICD-10. J. Clin. Psychiatry 1998, 59, $22-33$. [PubMed] 
36. Agresti, A.; Kateri, M. Categorical Data Analysis; Springer: Berlin/Heidelberg, Germany, 2011.

37. Simes, R.J. An improved Bonferroni procedure for multiple tests of significance. Biometrika 1986, 73, 751-754. [CrossRef]

38. Gauderman, W.J.; Murcray, C.; Gilliland, F.; Conti, D.V. Testing association between disease and multiple SNPs in a candidate gene. Genet. Epidemiol. 2007, 31, 383-395. [CrossRef] [PubMed]

39. Peterson, R.E.; Maes, H.H.; Holmans, P.; Sanders, A.R.; Levinson, D.F.; Shi, J.; Kendler, K.S.; Gejman, P.V.; Webb, B.T. Genetic risk sum score comprised of common polygenic variation is associated with body mass index. Hum. Genet. 2011, 129, 221-230. [CrossRef] [PubMed]

(C) 2017 by the authors; licensee MDPI, Basel, Switzerland. This article is an open access article distributed under the terms and conditions of the Creative Commons Attribution (CC-BY) license (http:/ / creativecommons.org/licenses/by/4.0/). 